\title{
Factors Related to Late Intrauterine Fetal Death in a Tertiary Referral Center: A Retrospective Study
}

\author{
Sandip Kuikel, Prezma Shrestha, Sunita Bajracharya, Sagar Poudel, Bijaya Thapa
}

\author{
Author Info: \\ Maharajgunj Medical \\ Campus, Tribhuvan \\ University Teaching \\ Hospital, Kathmandu \\ Nepal
}

\section{Corresponding Author: \\ Dr. Sandip Kuikel; Contact/Email: kuikelsandip@iom. edu.np}

00977-9849993770

\begin{abstract}
Background: Intrauterine fetal death is a contributor of perinatal outcome and is an important indicator of the quality of antenatal care. Despite efforts, risk factors cannot be identified in cases of intrauterine fetal deaths. This study aims to identify the maternal, fetal, placental and cord related factors related to it.
\end{abstract}

Methods: It is a retrospective cross-sectional study conducted analyzing patients admitted with intrauterine fetal deaths after 28 weeks of pregnancy at Tribhuwan University Teaching Hospital from April 2019 to March 2020 using in hospital admission records of the patient. It was conducted after taking ethical approval from Institutional Review Committee(IRC) of Institute of Medicine (IOM). Data were collected from review of charts of individual patients in MS Excel and was analyzed using SPSS.

Results: There were 5496 births and 46 intrauterine fetal deaths during the study period giving stillbirth rate of 8 per 1000 births. It was common in the age group of 26-30 years (34.8\%), 62.2\% were from inside Kathmandu valley,43.5\% were just literate, $13 \%$ were illiterate, $84.8 \%$ were housewives, $56.5 \%$ were primigravida and $69.57 \%$ of the babies were preterm. Only four percent had previous history of intra uterine fetal deaths. Hypertensive disorders complicating pregnancy were found in $30.5 \%$ followed by heart disease in $10.9 \%$ of the mothers. There were no known co-morbidities in $26.1 \%$ of the patients. Out of total 46 cases, $62 \%$ were female and $38 \%$ were male. Two had Rh isoimmunization and four had congenital malformations. Placenta previa was seen in four percent and abruptio placenta in two percent. Twin pregnancy with diamniotic dichorionic placenta was present in four percent. Seventeen percent of the babies had cord around the neck and two percent had thrombosis of the umbilical cord.

Conclusion: Low level of maternal education and maternal comorbidities like hypertensive disorders complicating pregnancy were found to be most common factors seen in cases of intrauterine fetal deaths.

Keywords: Intra Uterine Fetal Death (IUFD), risk factors, maternal factors, fetal factors

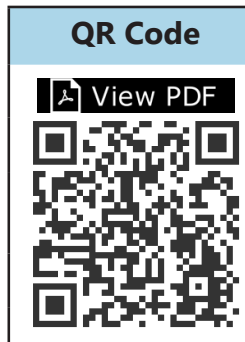

Scan Me

Received: 2 December 2020; Accepted: 9 February 2021;
How to cite this article in Vancouver Style?

Received: 2 December 2020

Kuikel S, Shrestha P, Bajracharya S, Poudel S, Thapa B. Factors related to late intrauterine fetal death in a tertiary referral center: A Retrospective Study . Europasian J Med Sci. 2021;3(1):34-39. https://doi.org/10.46405/ejms.v3i1.286

\section{Disclaimer}

Conflict of Interest: None Declared
Source of Support: Nil

Copyright $\subset 2021$ by author(s). This work is licensed under the terms and condition of Creative Commons Attribution International License 4.0@( $@$ (http://creativecommons.org/licenses/by/4.0/) which permits unrestricted use, distribution, and reproduction in any medium, provided the original work is properly cited. This is an open access publication, and can be downloaded freely from the website of the Journal: www.europasianjournals.org. The Journal as well as publisher remain neutral with regards to any jurisdictional claims in any published articles, its contents and the institutional affiliations of the authors. The Europasian Journal of Medical Sciences (EJMS) (www.europasianjournals.org) is an official Journal of Nirvana Psychosocial Care Center \& Ressearch Institute (www.nirvanapscc. $\underline{\mathrm{com})}$. 


\section{INTRODUCTION}

Fetal death is defined as death prior to complete expulsion or extraction of fetus irrespective of gestational age and is not induced termination of pregnancy. ${ }^{1}$ The Perinatal Mortality Surveillance Report (CEMACH) defined stillbirth as a baby delivered with no signs of life after completing 24 weeks' period of gestation. ${ }^{2}$ There are no uniform criteria to report Intra Uterine Fetal Death (IUFD). However, it is suggested to report fetal deaths at 20 or more weeks or weight greater than or equal to 350 grams if the gestational age is not known. ${ }^{3}$ In a developing country like Nepal, the period of viability for a fetus is later than that in a developed country and IUFD can be defined as fetal death occurring after 28 weeks period of gestation. ${ }^{4}$ Stillbirth is a significant contributor of perinatal mortality and is defined by $\mathrm{WHO}$ as the number of stillbirth and deaths in the first week of life per 1000 live births.

Globally, two million six hundred thousand stillbirths occurred in 2009 with at least half of all stillbirths occurred in the intrapartum period. ${ }^{5}$ Maternal, fetal, cord and placental factors play a major role in causing the death of a fetus in utero. Of those causes, the incidence of preeclampsia, feto-maternal hemorrhage, intrauterine growth retardation, congenital anomalies of fetus, chorioamnionitis, and cord accident are found to be relatively high..$^{6-8}$ Other risk factors may include maternal age, parity, socio-demographic and medical factors. ${ }^{9}$ Despite the current efforts, no clear etiology of stillbirth is identified in many cases. Since no cause can be identified, these deaths are difficult to prevent. This study aims to find out the prevalence, and identify and quantify the maternal, fetal, placental, and cord related factors in cases of IUFD admitted in Tribhuvan University Teaching Hospital (TUTH).

\section{MATERIALS AND METHODS}

This was a retrospective cross-sectional study conducted in TUTH, Nepal. It is a tertiary referral center of Nepal with adequate patient flow and receives a diversity of patients. This study was conducted after approval from the Institutional Review Committee of the Institute of Medicine. (Ref No.: 98(6-11)E2077/078) . Those cases with IUFD after 28weeks period of gestation (POG) or of fetal weight more than 500 grams in between April 2019 to March 2020 were identified from the labour room record book. All the charts of the identified cases were collected from medical record section and reviewed.. Those who had IUFD after 28 weeks' period of gestation (POG) or fetal weight more than 500 grams if the POG is not known; were the prime subject of the study. Gestational age was assigned based predominantly on the last menstrual period. Data related to mother, fetus, placenta, and cord were collected based on the chart. Data related to mother included maternal demographics (age, parity, period of gestation, occupation, and level of education), Antenatal Care (ANC), any co-morbidities like diabetes and hypertension, infections on the first trimester, history of IUFD and ruptured membrane for more than 12 hours.

Fetal data included sex of the baby, birth weight, Rh incompatibility, and any structural anomalies. Placental data and cord-related data included any pathology related to the placenta and the umbilical cord. All the demographic data included in the study were collected based on the charts available from Medial records of TUTH. Other data were obtained by reviewing individual records of the patients. All the data was entered in Microsoft Excel (Ver. 2016) and statistical analysis was performed using SPSS. The frequencies of maternal demographics, co-morbidities, baby weight, sex and gestational age, placental, and cord related risk factors were calculated.

\section{RESULT}

There were a total of 46 stillbirths among 5496 births during the study period. The calculated stillbirth rate was eight per 1000 births in our institution.

The average age of the mothers with still birth was $27.68(S D= \pm 5.98)$. Stillbirths were common in the age group of $26-30$ years (34.8\%), followed by 21 25 years (23.9\%). Most of the mothers (62.2\%) were from inside Kathmandu valley which is the main area of coverage of TUTH. Majority of mothers (43.5\%) were just literate to read and write their own names and do simple calculation, six (13\%) were illiterate and only a few (30.4\%) had secondary education and above. The majority (84.8\%) of patients were housewives (Table 1).

Out of 46 mothers, more than half of the mothers were primigravida $(56.5 \%)$ and the rest were multigravida (43.5\%). The period of gestation was less than 32 weeks in 20 cases (43.5\%); 32 to 37 weeks in 12 cases $(26.1 \%)$ and 37 to 42 weeks in 14 cases (30.4\%). The maximum period of gestation was 40 weeks 4 days whereas the mean period of 
Table 1: Demographic Characteristics of Mothers with Stillbirth

Characteristics Frequency (n) Percentage (\%)

\section{Age group}

20 or less

15.2

21-25

$7 \quad 15.2$

26-30

$11 \quad 23.9$

31-35

$16 \quad 34.8$

more than 35

6

Residence

Kathmandu

Outside of Kathmandu 17

Level of education

Illiterate

Just literate

37.8

Primary

Secondary

20

Above secon

Occupation

Housewife

Officer

Student

39

Teacher

\section{Parity of Mother}

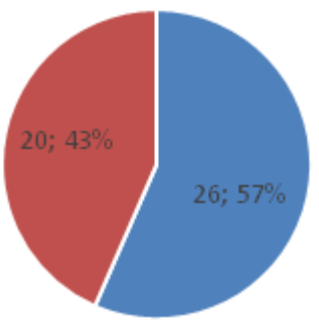

- Primi - Multi

Figure 1: Distribution of Parity of Mother

Previous history of IUFD

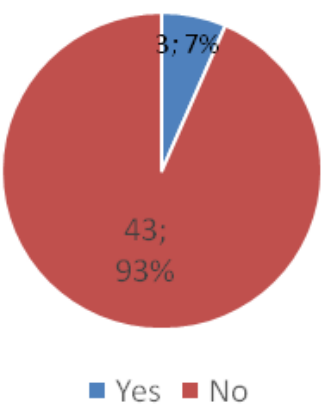

Figure 2: Past History of IUFD

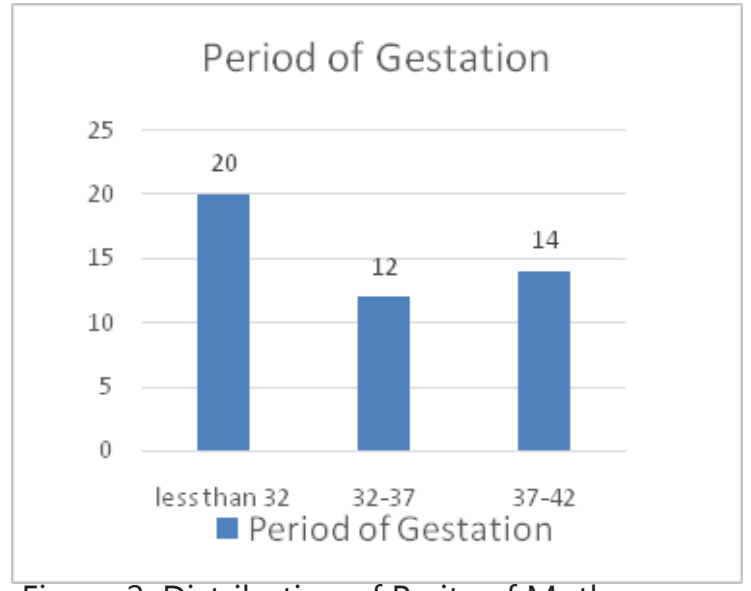

Figure 2: Distribution of Parity of Mother

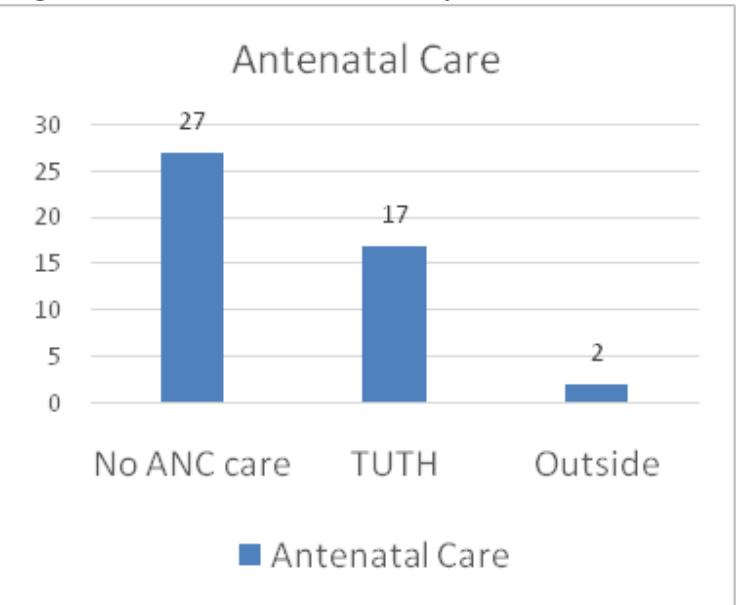

Figure 3: Distribution of Mother Visiting ANC gestation was 33 weeks. None of the mothers were postdated while $69.57 \%$ of the IUFD babies were preterm. Among the 46 IUFD cases, 27(58.7\%) were booked cases of TUTH, 17(37\%) were referred from outside and 2(4.3\%) had no antenatal visits. Two mothers (4.3\%) had a history of IUFD. (figure $1 \& 2$ ) Most of the mothers (30.5\%) with stillbirth had hypertensive disorders complicating pregnancy

\section{Table 2: Fetal Characteristics}

Characteristics Frequency Percentage(\%)

Weight (grams)

$\begin{array}{lll}<1000 & 12 & 26.1 \\ 1000 \text { to } 2000 & 12 & 26.1 \\ 2000 \text { to } 3000 & 14 & 30.4 \\ >3000 & 8 & 17.4 \\ \begin{array}{l}\text { Rh isoimmunization } \\ \text { Yes }\end{array} & & \\ \text { No } & 2 & 4.3 \\ \text { Fetal Anomalies } & 44 & 95.7 \\ \text { Yes } & & \\ \text { No } & 4 & 8.7 \\ \end{array}$




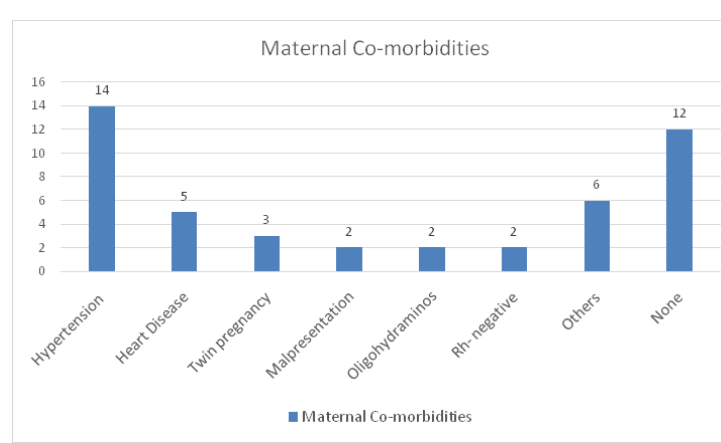

Figure 4: Maternal Co-morbidities

followed by heart disease (10.9\%) and multiple pregnancies (6.5\%). Oligohydramnios, Rh isoimmunization, hypothyroidism, obstetric cholestasis, polyhydramnios, pancytopenia, cholelithiasis and scrub typhus were amongst other

Table 3: Placenta and Cord Related Factors

\begin{tabular}{|c|c|c|}
\hline Characteristics & $c y(n)$ & $(\%)$ \\
\hline Placental pathology & & \\
\hline Placenta previa & 2 & 4.3 \\
\hline Abruptio placenta & 1 & 2.2 \\
\hline Diamniotic dichorionic & 2 & 4.3 \\
\hline Umbilical cord factors & & \\
\hline Cord around neck & 8 & 17.4 \\
\hline Thrombosis of umbilical cord & 1 & 2.2 \\
\hline
\end{tabular}

comorbidities in mother with IUFD. Twelve mothers (26.1\%) had no identified co-morbid conditions (figure 3, figure 4).

The majority of the IUFD babies were male (63\%). Most of the babies (30.4\%) weighed between 2000 and 3000 grams. Two babies (4.3\%) had Rh isoimmunization and four (8.7\%) had congenital malformations. All of the malformations noted were cardiac which included ventricular septal defect, atrial septal defect, and tetralogy of Fallot. One of the babies had associated duodenal atresia along with ventricular septal defect (table 2).

Placenta previa was seen in two cases (4.3\%) and abruptio placenta in one case (2.2\%). Twin pregnancy with diamniotic dichorionic placenta was present in two cases (4.3\%). Eight babies (17.4\%) had cord around the neck and one (2.2\%) had thrombosis of the umbilical cord. Four cases (8.7\%) with IUFD had thick meconium stained liquor (table 3).

\section{DISCUSSION}

Our study intended to find out the rate of IUFD in a tertiary referral center of Nepal along with maternal, fetal, placental and cord factors associated in cases of IUFD. In contrast to studies done in other centers of Nepal in which the rate of IUFD was found to be $14-23$ per 1000 births, our study showed a low rate of IUFD (8 per 1000 births). ${ }^{9-12}$ Different studies have been conducted in various parts of the world to identify the risk factors associated with IUFD. In a case-control study done in Iran comparing 150 cases of IUFD to 300 control with live births, it was found that mother's education, gestational age, consanguinity, ANC care, structural abnormalities, history of IUFD, cord prolapse, IUGR, and third trimester bleeding were statistically significant factors associated with IUFD.10 Another study analyzing 157 cases of singleton IUFD identified high number of patients with IUFD with lacking antenatal care, cord accidents, hypertension, diabetes, IUGR, abruptio placenta and previous history of IUFD. ${ }^{11}$

Advanced maternal age was shown to be an independent risk factor for IUFD by a crosssectional study using US CDC perinatal mortality data from 1995 to $1997 . .^{12}$ In this study done in TUTH, maternal age group of more than 35 years constituted $13 \%$ of the total IUFD cases.

In our study, $56.5 \%$ of the patients were primigravida. This result is comparable to studies done on BPKIHS and Dhulikhel hospital in which IUFD was seen more in primigravida and incidence of IUFD gradually decreased as the parity increased., ${ }^{4,13}$ This may be due to the level of knowledge about pregnancy and pregnancy-related care that the mother acquired on previous pregnancies.

Almost half of the patients with IUFD were illiterate or just literate to read and write their own names and do simple calculations while most of them were housewives. This finding is consistent with previous studies done in different parts of Nepal which had shown that mother's education as a significant factor for IUFD. ${ }^{4,14,15}$

Quality of care in the antenatal period directly affects the outcome of the fetus and mother. ${ }^{16,17}$ In our study, most mothers with IUFD had ANC care at least once either in our center or in the periphery. Most cases referred from outside presented late to our center and were complicated cases presenting with eclampsia, HELLP syndrome and heart disease.

In literature, studies have shown previous history of IUFD as a significant risk factor. A case-control study at the Maternity and Children's Hospital, Jeddah, Kingdom of Saudi Arabia showed 8.3\% patients with IUFD had previous history of IUFD. ${ }^{11} \mathrm{~A}$ retrospective study of singleton deliveries between the years 1988-2009 conducted by Ohana et al showed previous adverse perinatal outcome as 
a significant risk factor for IUFD. Our study also showed $6.5 \%$ of the patients had history of IUFD. ${ }^{18}$ This frequency is similar to above studies. However it is lower than the findings of the study by Kanavi et al. which showed $10 \%$ of patients with IUFD had history of one previous IUFD and $1.3 \%$ had history of two previous IUFDs. ${ }^{19}$

The study of BPKIHS done in 2014 identified hypertension as the most common maternal comorbidity in patients with IUFD. Other risk factors contributing to IUFD included antepartum hemorrhage, postdated pregnancy, Intrauterine growth restriction (IUGR), and sepsis. A relatively high number of patients had no identified risk factors. ${ }^{13}$ Similar studies conducted in different health care centers of Nepal also found hypertension as a significant risk factor for IUFD. ${ }^{4,14}$ Noteworthy, our study also showed similar results with a high incidence of hypertension complicating pregnancy followed by heart disease in mothers. There were no identifiable maternal comorbidities that may be responsible for IUFD in $26.1 \%$ of cases.

In our study most babies (69.57\%) were preterm, so the majority of the babies born were of low birth weight. This result is consistent with the findings of the study by Shrestha et al and Thakur et al where $66.67 \%$ and $53.3 \%$ of the babies born were preterms respectively. ${ }^{13,20} \mathrm{~A}$ similar study done in Nepalgunj Medical College showed $63.07 \%$ of the cases of IUFD were preterm and it is a significant risk factor for IUFD. Congenital malformations were evident in four cases of IUFD and are also shown to be significant risk factor for IUFD in previous studies. 13,14,21 When a Rh-negative mother is exposed to Rh-positive blood either through previous pregnancies or blood transfusion, she develops anti-D antibody (lgG) type which can cross the placental barrier causing fetal hemolysis.22 This is a significant risk factor of death of a fetus in utero. In our study out of 46 cases of IUFD, two mothers had Rh incompatibility.

Placental and cord-related pathologies that may lead to the demise of a fetus in utero include placenta previa, abruptio placenta, true knot, and umbilical cord thrombosis. $18,24,25$ In our study, two mothers had placenta previa and one had abruptio placenta. There were no cases of true umbilical cord knot. Cord around the neck and umbilical cord thrombosis were cord related factors found. Early diagnosis can help in identification of risk factors and complications associated with IUFD. This helps in identification of the high risk population along with reduction of interventions required. ${ }^{13}$

\section{CONCLUSION}

The majority of risk factors for intrauterine fetal death like hypertension are preventable. Early detection of high-risk pregnancy and timely management can reduce the rate of IUFD and improve perinatal outcome. Regular antenatal checkups in a health institution should be highly encouraged. For this maternal education plays a vital role. Emphasis on health education to females of reproductive age group can reduce the burden of stillbirth.

\section{REFERENCES}

1. National Center for Health Statistics, 1997. Kowaleski J. State definitions and reporting requirements for live births, fetal deaths, and induced terminations of pregnancy (1997 revision). 1997. Available from: https://www. cdc.gov/nchs/data/misc/itop97.pdf

2. Cox S, Golightly S, Sullivan A. Confidential Enquiry into Maternal and Child Health (CEMACH) Perinatal Mortality 2007: United Kingdom. London: CEMACH. 2009; Available from: https://www.oaa-anaes.ac.uk/assets/ managed/editor/File/Reports/2007 Perinatal mortality.pdf

3. Metz TD, Berry RS, Fretts RC, Reddy UM, Turrentine MA, Gynecologists $A C$ of $O$ and. Obstetric Care Consensus\# 10: Management of Stillbirth:(Replaces Practice Bulletin Number 102, March 2009). Am J Obstet Gynecol. 2020;222(3):B2-20. https://doi.org/10.1016/j. ajog.2020.01.017

4. Tamrakar SR, Chawla C. Intrauterine Foetal Death and Its Probable Causes: Two Years Experience in Dhulikhel Hospital - Kathmandu University Hospital. Kathmandu Univ Med J (KUMJ). 2014 Sep 9;10:44-8. https://doi. org/10.3126/kumj.v10i4.10994

5. World Health Organization (WHO). Maternal newborn, child and adolescent health. [cited 2020 Dec 10]. https://www.who.int/maternal_ child_adolescent/epidemiology/stillbirth/en/

6. Yamauchi A, Minakami H, Ohkuchi A, Usui R, Idei S, Sato I. Causes of stillbirth: an analysis of 77 cases. J Obstet Gynaecol Res. 1999;25(6):41924. https://doi.org/10.1111/j.1447-0756.1999. tb01187.x

7. Man J, Hutchinson JC, Heazell AE, Ashworth M, Levine S, Sebire NJ. Stillbirth and intrauterine fetal death: factors affecting determination of 
cause of death at autopsy. Ultrasound Obstet Gynecol. 2016;48(5):566-73. https://doi. org/10.1002/uog.16016

8. Hematyar M, Yarjou S. Causes of perinatal mortality at Javaheri hospital during a 7-year period 1996-2003. Med Sci J Islam Azad Univesity-Tehran Med Branch. 2005;15(1):3740. http://tmuj.iautmu.ac.ir/article-1-260-en. html

9. Zhang J, Cai W. Risk factors associated with antepartum fetal death. Early Hum Dev. 1992;28(3):193-200. https://doi. org/10.1016/0378-3782(92)90166-E

10. Journal SE. Risk factors related to intra uterine fetal death in Iran, A case-control study. Introduction: Materials and Methods: 2005;6(3):1-14. https://sites.kowsarpub.com/ semj/articles/78575.html

11. Shaaban LA, Al-Saleh RA, Alwafi BM, AlRaddadi RM. Associated risk factors with antepartum intra-uterine fetal death. Saudi Med J. 2006;27(1):76-9.

12. Bahtiyar MO, Funai EF, Rosenberg V, Norwitz E, Lipkind $\mathrm{H}$, Buhimschi $\mathrm{C}$, et al. Stillbirth at term in women of advanced maternal age in the United States: When could the antenatal testing be initiated? Am J Perinatol. 2008;25(5):301-4. http://doi.org/10.1055/s-2008-1076605

13. Thakur A, Basnet P, Rai R, Agrawal A. Risk Factors Related to Intrauterine Fetal Death. J Nepal Health Res Counc. 2019;17(1):46-50. https://doi.org/10.33314/jnhrc.v17i01.1534

14. Sinha K, Pandey S. Risk Factors in Patients with Intrauterine Fetal Death at Tertiary Referral Centre. J Nepalgunj Med Coll. 2019;17(2):14-6. https://doi.org/10.3126/jngmc.v17i2.28752

15. Pradhan P, Poudel S, Maharjan A. Still-birth--a tragic journey: a critical analysis. Nepal Med Coll J. 2010;12(4):239-43.

16. Ronsmans C, Graham WJ, group LMSS steering. Maternal mortality: who, when, where, and why. Lancet. 2006;368(9542):1189-200. https:// doi.org/10.1016/S0140-6736(06)69380-X

17. Tuladhar $\mathrm{H}$, Dhakal N. Impact of antenatal care on maternal and perinatal utcome: a study at Nepal medical college teaching hospital. Nepal J Obstet Gynaecol. 2011;6(2):37-43. http:// dx.doi.org/10.3126/njog.v6i2.6755

18. Ohana O, Holcberg G, Sergienko R, Sheiner E. Risk factors for intrauterine fetal death (1988-
2009). J Matern Neonatal Med. 2011 Sep 1;24(9):1079-83. https://doi.org/10.3109/1476 7058.2010.545918

19. Kanavi J V, G S, G K. Incidence and Risk Factors for Intrauterine Foetal Demise: a Retrospective Study in a Tertiary Care Centre in India. Int J Pregnancy Child Birth. 2017;2(2):2015-8. https://doi.org/10.15406/ipcb.2017.02.00013

20. Shrestha S, Yadav B. Risk Factors associated with Still Births. JNMA J Nepal Med Assoc. 2010 Mar 1;49:84-7. PMid: 21180228

21. Jamal S, Agarwal S. IUFD incidence, causes and complications: a retrospective study done at a tertiary care centre in greater Noida, India. Int J Reprod contraception, Obstet Gynecol. 2017;6(12):5484. http://dx.doi. org/10.18203/2320-1770.ijrcog20175265

22. Costumbrado J, Mansour T, Ghassemzadeh S. Rh incompatibility. 2019

23. Ben-David G, Sheiner E, Levy A, Erez O, Mazor $M$. An increased risk for non allo-immunization related intrauterine fetal death in RhDnegative patients. J Matern neonatal Med Off J Eur Assoc Perinat Med Fed Asia Ocean Perinat Soc Int Soc Perinat Obstet. 2008; 21(4):255-9. https://doi.org/10.1080/14767050801928804

24. Singh $V$, Khanum $S$, Singh $M$. Umbilical cord lesions in early intrauterine fetal demise. Arch Pathol Lab Med. 2003;127(7):850-3. https:// doi.org/10.1043/1543-2165(2003)127<850:UC LIIEI>2.0.CO;2

25. Ikechebelu J, Eleje G, Ofojebe C. True umbilical cord knot leading to fetal demise. Ann Med Health Sci Res. 2014 Jul;4(Suppl 2):S155-8. https://doi.org/10.4103/2141-9248.138044 